\title{
B-TYPE NATRIURETIC PEPTIDE AS BIOMARKER OF FETAL CARDIOVASCULAR DISTRESS
}

\author{
D.C. Vijlbrief ${ }^{1}$, M.J.N.L. Benders ${ }^{1}$, H. Kemperman ${ }^{2}$, F. van Bel ${ }^{1}$, W.B. de Vries $^{1}$ \\ ${ }^{I}$ Neonatology, ${ }^{2}$ Clinical Chemistry and Hematology, University Medical Center Utrecht, Utrecht, The \\ Netherlands
}

Background: Early life exposure to a (chronic) hypoxic incident may predispose to adult cardiovascular risk. Identifying those at risk is difficult. Impairment of gas exchange and blood flow through the placenta leads to hypoxia and hypercapnia. If hypoxia persists, depletion of energy reserves and anaerobic metabolism with lactate acidosis directly affects myocardial contractility. B-type natriuretic peptide (BNP), a biomarker of ventricular strain, is used to recognise cardiocirculatory failure.

Objective: To find those perinatal factors associated with cardiovascular compromise in the early newborn period.

Methods: In infants born from October 2009 until October 2010 with $\mathrm{GA}<32$ weeks BNP-levels were measured within 6 hours after birth. BNP-levels were related to factors associated with acute and chronic fetal hypoxia.

Results: 164 infants were included. BNP (median $69.5 \mathrm{pmol} / \mathrm{L}$,range 4-1985) was related to those factors associated with chronic asphyxia (Nucleated red blood cells; $\mathrm{r}=0.339, \mathrm{p}<0.001$, Intra-uterine growth retardation (IUGR); $\mathrm{r}=0.344, \mathrm{p}<0.001$ ), and with acute asphyxia (Umbilical artery $\mathrm{pH} ; \mathrm{r}=0.379, \mathrm{p}<0.001$, Serum lactate; $\mathrm{r}=0.419, \mathrm{p}<0.001$ and 1 minute Apgar scores; $\mathrm{r}=0.309, \mathrm{p}<0.001$ ). BNP was especially elevated in those infants where IUGR coincided with perinatal signs of fetal distress (figure 1).

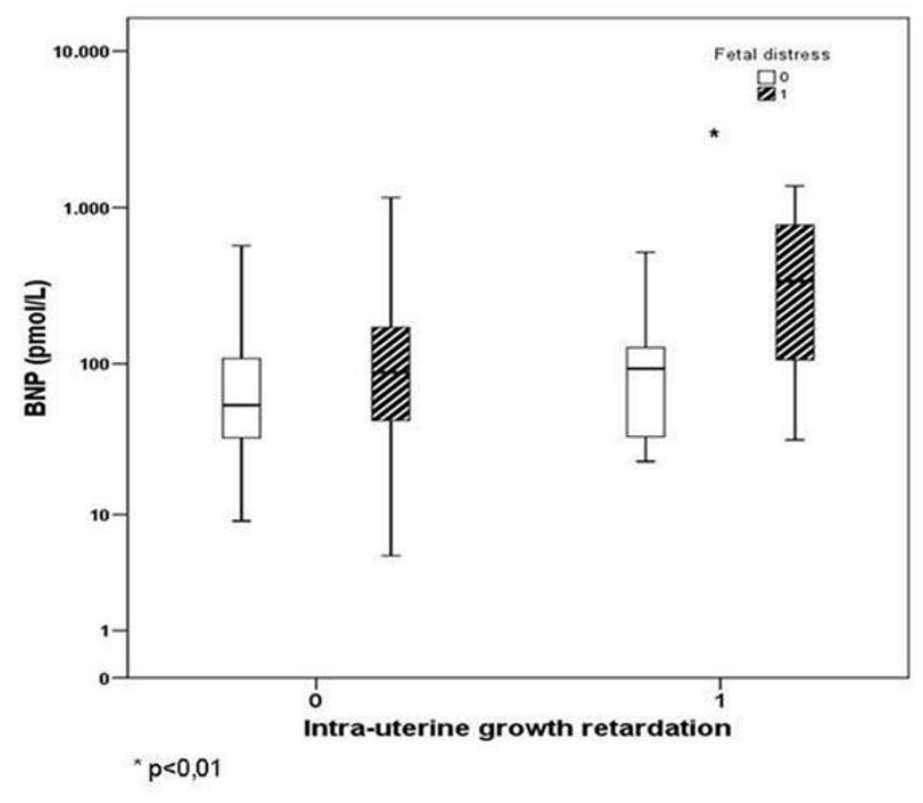

[Figure 1]

Conclusion: Elevated levels of BNP after birth in premature infants can identify significant cardiocirculatory compromise during the late fetal period and possibly identify those at risk for cardiovascular problems in the (near) future. 